\title{
Condenação de carcaças suínas por caudofagia em frigorífico sob Inspeção Federal no município de Concórdia, Santa Catarina
}

Condemnation of swine carcasses due to caudophagy in the slaughter-storage operations under the Federal Inspection, in Concórdia district in Santa Catarina

Dionara Pinto Braga, Ana Elisa Del'Arco \& Roberta Costa Dias

\section{RESUMO}

A importância da caudofagia se dá pelos prejuízos sanitários e econômicos que acarreta, mesmo com a sua incidência sendo pequena em relação a outras doenças. O objetivo deste trabalho foi mostrar a frequiência de condenação de carcaças suínas por caudofagia no matadouro-frigorífico sob Inspeção Federal SIF 1 situado no município de Concórdia em Santa Catarina, fazendo um acompanhamento da inspeção ante-mortem e post-mortem de 410.123 animais, no período de janeiro a maio de 2006, onde 2,13\% dos animais enviados ao Departamento de Inspeção Final (DIF) foram condenados por caudofagia. O problema pode ter sido causado por falhas no manejo, problemas nutricionais, alta densidade animal, excesso de umidade ou falta de subsídios para os animais desenvolverem suas ações exploratórias. Tudo isso implicou em um bem estar suíno pobre, que refletiu em um significante prejuízo para os produtores e para a indústria, mostrando a importância de melhorias nas técnicas de confinamento da suinocultura moderna.

Descritores: suínos, canibalismo, comportamento, bem estar.

\begin{abstract}
The importance of caudophagy, or tail-biting, in swine production arises from the detrimental sanitary and economic consequences that accompany it, despite its low incidence in relation to other diseases. The objective of this work was to determine the frequency of the condemnation of swine carcasses due to caudophagy in the slaughter-storage operations under the Federal Inspection SIF 1 situated in the Concórdia district in Santa Catarina. The ante-mortem and post-mortem inspections of 401,123 animals were accompanied from January to May 2006, during which period $2.13 \%$ of animals sent to the Final Inspection Department were condemned because of caudophagy. The problem may have been caused by faulty management, nutritional deficiencies, high animal density, excessive humidity or limited opportunities for the development of positive social interaction among the animals. All of these factors indicate low swine well-being, which imparts a significant risk to both the producers and for the industry, illustrating the significance of improvements in techniques of confinement in modern swine production.
\end{abstract}

Key words: swine, cannibalism, behavior, animal welfare. 


\section{INTRODUÇÃO}

A mordedura de cauda é um problema de grande importância na produção suína, devido a consideráveis prejuízos sanitários e econômicos que acarreta [10], como: menor ganho de peso, formação de abscessos principalmente nas vértebras, perdas de animais por paralisia do trem posterior e condenação de carcaças em matadouros frigoríficos [12]. Além disso, pode ser considerado um importante indicador de bem-estar no sistema de produção [3]. O problema parece difundido e a incidência pode ter aumentado com a intensificação dos sistemas de criação e o melhoramento genético [2,4,12]. $\mathrm{O}$ aparecimento da caudofagia pode ser atribuído a inúmeros fatores, incluindo o ambiente físico, climático e o manejo nutricional [4]. A privação de estímulos ambientais (ambiente monótono, falta de substratos, palha, ramos ou terra) leva à frustração, que pode se refletir em comportamentos anômalos ou estereótipos. Num ambiente monótono o animal senta, balança a cabeça e cauda e, na ausência de ambiente para explorar, pratica o canibalismo $[7,8]$.

O presente trabalho teve por objetivo observar a freqüência de condenação de carcaças por caudofagia durante o abate de suínos, no frigorífico sob inspeção federal SIF 1, situado no município de Concórdia, Santa Catarina.

\section{MATERIAIS E MÉTODOS}

Foram coletados dados de abate do período de janeiro a maio de 2006, no matadouro frigorífico de aves e suínos, sob Inspeção Federal, SIF 1 situado no município de Concórdia, Santa Catarina. A coleta de dados primários ocorreu entre os meses de abril a maio de 2006, quando foram acompanhados os abates. Os dados referentes aos outros meses são secundários, fornecidos pelo banco de dados da inspeção.

Nos meses em que foi realizado o acompanhamento dos abates, esse ocorreu desde a inspeção antemortem, onde os animais com lesões acentuadas eram sacrificados e destinados à graxaria. Os animais aparentemente saudáveis eram encaminhados para o corredor de insensibilização e posteriormente eram sangrados, escaldados, depilados, eviscerados e realizada a inspeção post-mortem. Nesta etapa foram acompanhadas todas as linhas de inspeção. As carcaças com lesões eram enviadas para o Departamento de Inspeção Final (DIF), onde era realizada uma inspeção minuciosa e dado o destino das carcaças para banha, produto cozido ou graxaria dependendo da extensão do problema. Os dados foram analisado pelo programa SPSS, versão 8.

\section{RESULTADOS}

Foram abatidos no período de janeiro a maio de 2006410.123 animais, dos quais foram desviados para o DIF 34.194 carcaças $(8,34 \%)$. Desses animais, 727 foram desviados devido à caudofagia $(2,13 \%)$. Além da caudofagia houve outras condenações importantes como por artrite $(4,38 \%)$ e por pneumonia $(10,38 \%)$. Como procedimento de inspeção foi realizado um corte ao longo da coluna, desde as vértebras coccicais até as vértebras cervicais, na lateral direita e esquerda para observar presença de abscessos. Com as observações realizadas, as carcaças condenadas por caudofagia tinham seu destino direcionado dependendo da extensão da lesão. Para banha foram enviadas 211 carcaças que apresentavam abscessos em mais de um local, 132 carcaças foram destinadas à graxaria, pois apresentavam abscessos na musculatura em vários locais e em alguns órgãos. Foram destinados a produto cozido 384 carcaças que apresentavam abscesso em somente um local, geralmente na base da cauda.

\section{DISCUSSÃO}

Na rotina de inspeção, o destino da carcaça com abscessos por caudofagia, é previsto no artigo 157 do RIISPOA já que essa alteração não determina a condenação da carcaça [1]. Os abscessos podem ser focais ou multifocais e se apresentam mais comumente na coluna vertebral, no fígado, rins, coração e pulmões. Em um estudo realizado na Irlanda do Norte os abscessos de pulmão não tinham extensão além de doença pulmonar e quase todas as lesões eram pequenas e múltiplas [5].

Apesar da porcentagem de condenação por caudofagia não ser tão expressiva como por outros problemas $(p<0,001)$, ela é relevante, pois significa a condenação total da carcaça, além de refletir problemas no sistema de produção que podem ser controlados. Além disso, os dados referentes à condenação por caudofagia podem estar subestimados já que no momento da inspeção ante-mortem os animais com feridas cruentas de caudofagia são condenados, não sendo abatidos e são computados como carcaça condenada em planilha separada, a qual não se teve acesso.

A compreensão da verdadeira causa da caudofagia é difícil devido a sua ocorrência esporádica e imprevisível [3]. A importância do bem-estar animal 
relacionado a este problema traz uma nova realidade, da qual os produtores deverão conscientizar-se [5].

Com relação ao meio ambiente de criação, um dos fatores predisponentes mais importantes é o excesso de umidade. Grande número de casos de canibalismo são verificados após um período de aumento da umidade relativa do ar em dias frios [11,12]. Quando um rebanho de suínos vive em condições de superpopulação em um ambiente muito úmido, o vapor aquoso se condensa na ponta da cauda e esta contínua umidade cria um meio de cultivo favorável ao desenvolvimento do bacilo Fusiformes necrophorus, responsável pela necrose na ponta da cauda. Esta lesão estimula os leitões a mordiscar o tecido necrosado [10]. Outros problemas ambientais podem ser as más condições de higiene, acúmulo de dejetos na instalação, ventilação deficiente e temperatura interna das instalações muito elevada [10,12]. O tipo de ventilação tem um efeito significante na probabilidade de ocorrer a caudofagia. Estudos mostram que a ventilação natural reduziu a ocorrência do problema, com o efeito sendo mais marcante para os suínos nos quais a cauda não foi cortada [6]. A alta densidade e tamanho dos grupos também aumentam a probabilidade da aparição de caudofagia [11,13]. Em um estudo realizado no Reino Unido observou-se que densidades iguais ou maiores que 1,1 animais $/ \mathrm{m}^{2}$ multiplicam por três a probabilidade de surgimento do problema [13]. Observando as instalações e o sistema de criação comum na região sul, pode-se dizer que esta deve ser uma causa importante do surgimento da caudofagia, já que a maioria dos pequenos produtores possui instalações antigas que não favorecem a ventilação e conseqüentemente ocorre o acúmulo de umidade dentro do galpão. Além disso, não é raro observar produções de suínos trabalhando com densidades de animais superiores ao recomendado.

A alimentação desequilibrada é considerada pela maioria dos criadores como a principal causa de caudofagia. Erros na composição ou mistura dos concentrados ou das rações, na quantidade de alimento fornecido aos animais ou o fornecimento do alimento em horas variadas são tidos como os fatores mais frequientes. $\mathrm{O}$ erro no fornecimento leva a inquietação motivada pela espera o que pode desencadear o canibalismo. Os erros nutricionais podem ser por excesso de energia ou proteína animal, deficiência de proteína ou fibra, porcentagem de cloreto de sódio abaixo de $0,3 \%$, porcentagem de cálcio abaixo de $0,8 \%$ ou acima de $2 \%$ [12]. Verificou-se nos suínos e também em outras espécies que o estresse provoca uma maior necessidade pelo sal. Essa carência estimularia condutas exploratórias facilitando a aparição de caudofagia, e ou o agravaria em caso do surgimento, dada a tendência da formação de feridas sangrantes devido a baixa concentração de sal do sangue. Como a suinocultura brasileira trabalha com as mais altas tecnologias e conhecimentos relacionados à nutrição animal, nesse caso pode-se dizer que provavelmente o erro na formulação das dietas não deve ser a principal causa do problema encontrado. Mas o manejo de alimentação controlada nas fases de crescimento e terminação pode sim ser um indicativo, já que os animais sob este manejo não recebem alimento à vontade, podendo sentir fome em determinados horários do dia.

Estudos mostram que, em infestações e infecções por parasitoses, anemia por deficiência de ferro, cobalto ou cobre e no caso de infecções bacterianas (por exemplo por Streptococcus sp.), tem-se observado maior frequiência de canibalismo, não pela doença, mas sim pela intranqüilidade e irritabilidade dos animais [10,12]. Sabe-se que trabalhar com sistemas de produção completamente livre de patógenos é uma situação difícil de ser alcançada. Seria necessário um acompanhamento mais detalhado dos sistemas de criação para poder estabelecer esta relação com maior confiabilidade entre estes fatores.

Um estudo realizado na Universidade Autônoma de Barcelona na Espanha avaliou que o piso ripado também aparece como claro fator de risco, tendo uma probabilidade três vezes maior de aparição da caudofagia comparado com piso contínuo. Observou-se que no piso ripado os animais não expressaram as condutas exploratórias que são normais no comportamento dos suínos [11,13]. A palha é outro importante componente ambiental, que influencia favoravelmente o bem-estar animal. Nos sistemas confinados, o uso de palha ou outro substrato similar cobrindo o piso, pode diminuir a manifestação comportamental, dos chamados "vícios" entre os animais [7,8]. A relação entre caudofagia e a presença de outros materiais (palha, correntes, etc.) que permitam as condutas exploratórias é bastante estudada, e a presença desses materiais reduz entre 10 e 12 vezes a probabilidade de surgimento da caudofagia. Em alguns casos, inclusive, conseguese eliminar o problema oferecendo aos animais subsídios para condutas exploratórias [13]. A prática de 
fornecer materiais para conduta exploratória ainda não é adotada por todos os produtores não dando a devida importância a um ambiente adequado a esses animais, muitas vezes pela falta de conhecimento da importância da sua utilização. $\mathrm{O}$ sistema de produção em cama sobreposta possui esta vantagem em relação ao sistema tradicional de produção de terminados.

Comparativamente com o confinamento intensivo, o sistema de criação intensivo do suíno ao ar livre (SISCAL) apresenta muito menos problemas comportamentais. A ocorrência de comportamentos anômalos, canibalismo e agressão no sistema ao ar livre foi muito menor do que no confinado, indicando melhor bem estar animal $[7,8]$. Isto ocorre porque ao ar livre o suíno tem um ambiente onde pode desenvolver atividades normais o que não acontece no sistema confinado da suinocultura moderna. No Brasil o SISCAL ainda é pouco utilizado, porque necessita de uma maior área para produção, o que inviabiliza muitas vezes a sua implantação. Além disso, na maioria das vezes esse sistema possui produtividade menor quando comparado ao sistema totalmente confinado, ponto importante para escolha do sistema de produção adotado.

O corte de cauda é uma técnica de manejo bastante utilizada entre os produtores como medida de prevenção na ocorrência da caudofagia. A ponta da cauda tem pouca sensibilidade e o suíno, geralmente, não reage quando seu companheiro de cela a morde. Ao eliminarmos esta parte da cauda, o suíno ao ser mordido sentirá dor e reagirá, evitando assim a agressão. O problema é a possibilidade de causar dor crônica dependo da técnica utilizada para o corte da cauda $[3,12]$. Alguns autores ressaltam que isso pode, no momento, reduzir a incidência de caudofagia ou somente mascarar o problema, partindo do pressuposto que, a parte da cauda que fica, basta para estimular o vício, se ao mesmo tempo não se corrigir outros fatores predisponentes no sistema de produção [3,10,11,12].
Diante do exposto os problemas que podem levar a caudofagia sempre estão relacionados ao bemestar, principalmente aqueles que levam a condições de criação que favoreçam o estresse nos animais. $\mathrm{O}$ bem-estar está relacionado com o conforto físico e mental. É difícil saber o grau de satisfação do animal com seu ambiente. Conforto físico implica o animal estar saudável e em bom estado corporal. O animal pode estar em ótimas condições físicas, saudável e bem nutrido, mas estar sendo criado em condições de estresse que não interferem no seu ganho de peso, mas que é suficiente para desencadear problemas comportamentais [8]. A suinocultura brasileira atual é uma produção altamente tecnificada, com a grande maioria das produções trabalhando dentro do sistema intensivo totalmente confinado, que gera em algum momento da produção um certo nível de estresse, como descrito anteriormente.

$\mathrm{O}$ bem-estar dos animais, juntamente com as questões ambientais e a segurança dos alimentos é considerado um dos maiores desafios da agropecuária mundial. A convicção dos consumidores de que os animais utilizados para a produção de alimentos devem ser bem tratados, ganha cada vez mais importância, principalmente junto à União Européia (UE) [9]. Embora esse movimento seja hoje liderado por uma parcela minoritária da população, as demandas do público, cada vez mais urbano, são crescentes, devendo os produtores, técnicos e a indústria ter atitudes para suprir essa demanda [8].

\section{CONCLUSÃO}

A condenação por caudofagia foi de $2,13 \%$ podendo ser considerada baixa ao comparar-se com as outras causas de condenação observadas, mas é um dos problemas que levam a condenação de carcaças no matadouro-frigorifico SIF 1. Esta condenação reflete uma importância para a produção, pois é um reflexo do bem estar dos animais.

\section{REFERÊNCIAS}

1 BRASIL. Ministério da Agricultura Pecuária e Abastecimento/DIPOA. Regulamento de Inspeção Sanitária de Produtos de Origem Animal. Inspetoria do Sipama (Aprovado pelo Decreto nº30.691 de 29/03/52, alterado pelos decretos $n^{\circ} 1.255$ de 25/06/62, nº1.236 de 02/09/94, nº1.812 de 08/02/96 e n².244 de 04/06/1997) Brasília, 1997.

2 Breuer K., Sutcliffe M.E.M., Mercer J.T., Rance K.A., O’Connell N.E., Sneddon I.A. \& Edwards S.A. 2005. Heritability of clinical tail biting and its relation to performance traits. Livestock Production Science. 93: 87-94.

3 Edwards S.A. 2006. Tail biting in pigs: Understanding the intractable problem. The Veterinary Journal. 171: 198-199.

4 Hemsworth P.H. 1992. Behavioral Problems. In: Leman A. D., Straw B. E., Mengeling W. L., D’ Allaire S. \& Taylor D. J. (Eds). Diseases of swine. 7.ed. Canada: Wolfe Publishing, pp 655-656. 
5 Huey R.J. 1996. Incidence, location and interrelationships between the sites of abscesses recorded in pigs at a bacon factory in Northern Ireland. The Veterinary Record. 138: 511-514.

6 Hunter E.J., Jones T.A., Guise H.J., Penny H.C. \& Hoste S. 2001. The relationship between tail biting in pigs, docking procedure and other management practices. The Veterinary Journal.161: 72-79.

7 Machado Filho L.C.P. \& Hötzel M.J. 2001. As porcas gestantes merecem conforto. Pork World. (02): 22-24.

8 Machado Filho L.C.P. \& Hötzel M.J. 2006. Bem-estar dos suínos. Disponível em: http://www.uov.com.br/central_aluno/ biblioteca/Curso25-6.pdf>. Acessado em 06/2006.

9 Pandorfi H. 2006. Bem-estar animal na produção industrial de suínos: Ética na produção e segurança dos alimentos. Núcleo de pesquisa em ambiência. Universidade de São Paulo. Disponível em: <http://www.nupea.esalq.usp.br/bemestarsuinos.htm>. Acessado em 06/2006.

10 Price W.T. 1973. Hábitos viciosos. In: Patología Porcina en Imagenes. 1.ed. Barcelona: GEA, pp.122-125.

11 Schroder-Peterson D.L. \& Simonsen H.B. 2001. Tail Biting in Pigs. The Veterinary Journal. 162: 196-210.

12 Sobestiansky J., Barcelos D.E.S.N., Oliveira S.J., Carvalho L.F.O.S., Moreno A.M. \& Roehe P.M. 2001. Formas anormais de comportamento. In: Patologia e clínica suína. 2.ed. Goiânia: Gráfica Art3, pp.178-181.

13 Torre L.R. \& Manteca X. 2004. Factores de riesgo en las explotaciones y prevención de la caudofagia. Universidad Autónoma de Barcelona. España. 3p. Disponível em: <http://www.3tres3.com/comportamiento/ficha.php?id=19>. Acessado em 06/2006. 